\title{
The Efficacy of Thyrotropin Suppression Therapy in Treatment of Differentiated Thyroid Cancer after Total Thyroidectomy
}

\author{
Niveen A. Abo-Touk", M.D.; Dalia H. Zayed, M.D. \\ The Department of Clinical Oncology \& Nuclear Medicine, \\ Faculty of Medicine, Mansoura University, Egypt
}

\begin{abstract}
Background: The aim of this prospective study was to assess the effect of the TSH suppression on both disease-free and overall survivals in patients with nonmetastatic differentiated thyroid cancer (DTC) after total thyroidectomy.

Patients \& Methods: One hundred and forty eight patients with pathologically proved operable differentiated thyroid carcinoma were enrolled in this prospective study. Levothyroxin (L-T4) therapy was started in doses according to treatment groups. Patients were randomly assigned to receive either postoperative TSH suppression therapy in group I (76 patients) or nonsuppression therapy in group II (72 patients).

Results: During the period of follow up with a median 54 months, the disease-free survival for patients without TSH suppression therapy did not reach statistically significant difference comparing with those for patients with the suppression therapy $(p=0.09)$. However, the difference was statistically significant for high-risk patients $(p=0.04)$. On comparing both groups there was no statistically significant difference with regard to overall survival $(p=0.17)$. The age of the patients more than 45 years, tumour size more than $4 \mathrm{~cm}$ and high-risk group were significant independent predictors for thyroid carcinoma-related relapse in univariate analysis. However, tumour size was the only significant factor in multivariate analysis.

Conclusion: Suppressive treatment with L-T4 therapy in patients with differentiated thyroid carcinoma should be individualised and balanced against the adverse effects. TSH suppression is indicated in patients with high-risk disease or recurrent tumour. Normalisation of serum TSH is preferred for long-term treatment of disease-free elderly patients with DTC and comorbidities.
\end{abstract}

Keywords: Thyroid cancer • differentiated thyroid cancer • TSH suppression • thyroxin therapy

(c) De Gruyter Open

\section{Introduction}

Thyroid carcinoma is the most common endocrine malignancy. An estimated number of thyroid cancer cases in Egypt were 2306 patients in 2013 [1]. Differentiated thyroid cancer (DTC), which includes papillary and follicular cancer, comprises the vast majority (90\%) of all thyroid cancers [2]. The 10-year relative survival rates for patients with papillary, follicular and Hurthle cell carcinomas were $93 \%, 85 \%$ and $76 \%$, respectively [3].

Apart from solitary well-differentiated thyroid cancer less than $1 \mathrm{~cm}$ in diameter with no evidence for nodal or distant metastases, and no history of previous radiation exposure that may be operated on by less than total thyroidectomy, the standard surgical treatment is total (or near-total) thyroidectomy. This procedure decreases the risk of local recurrence and is performed with almost no morbidity under expert hands. Moreover, it facilitates adequate follow-up [4]. Completeness of surgical resection is an important determinant of outcome. Postoperative ${ }^{131}$ I thyroid remnant ablation is considered when the patient has a tumour with a significant potential for recurrence. Remnant ablation may destroy residual normal follicular cells destined to become malignant and occult cancer that might recur years later [5].

Ablation of the small amount of residual normal thyroid remaining after total thyroidectomy may help in the early detection of recurrence based on serum thyroglobulin ( $\mathrm{Tg}$ ) measurement and radioactive iodine whole-body scan. Additionally, the post-therapy scan obtained at the 
time of remnant ablation may facilitate initial staging by identifying previously undiagnosed disease, especially in the lateral neck [6].

Postoperative staging allows the risk stratification of individual patients, which in turn will dictate the frequency and type of follow-up [7]. Suppression of TSH, using supraphysiologic doses of levothyroxin (L-T4), is used commonly to treat patients with thyroid cancer in an effort to decrease the risk of recurrence [8]. The role of TSH-suppressive therapy after initial treatment is to correct the hypothyroidism using a dosage appropriate to achieve normal blood levels of thyroid hormones; the second aim is to inhibit the TSH-dependent growth of residual cancer cells by decreasing the serum TSH level to $\leq 0.1 \mu \mathrm{lU} / \mathrm{ml}[9]$.

However, TSH suppressive therapy is controversial because of the excellent curative prognosis of low-risk DTC and the eventual harmful effects of the subclinical thyrotoxicosis state to which patients are subjected over a long period of time [10]. Side effects of TSH suppression may include the known consequences of subclinical thyrotoxicosis, including exacerbation of angina in patients with ischemic heart disease, increased risk for atrial fibrillation in older patients and increased risk of osteoporosis in postmenopausal women [11,12]. The risk and benefit of TSH suppression therapy must be balanced for each patient [13]. We prospectively assessed the efficacy of TSH suppression therapy on disease-free and overall survivals in patients with nonmetastatic differentiated thyroid cancer after total thyroidectomy.

\section{Patients and methods}

\section{Inclusion criteria}

Patients aged from 18 to 70 years with pathologically confirmed operable differentiated thyroid carcinoma who presented to the department of Clinical Oncology \& Nuclear Medicine, Mansoura University Hospital, were enrolled in this prospective study during the period between November 2006 and December 2010, inclusive. No patients had family history or prior malignancies or received neck irradiation.

All patients were aimed to be treated with total or near total thyroidectomy and lymph nodes surgery was performed according to their presentation. A modified radical neck dissection (removal of neck lymph nodes with preservation of sterno-cleidomastoid muscle, internal jugular vein and accessory nerve) was performed at thyroidectomy if there were lymph node metastases at presentation. When lymph node metastases were not detected before surgery, neck inspection was done during thyroidectomy, and suspected lymph nodes were removed. If lymph node metastasis was confirmed, a modified radical neck dissection would be done. Completion thyroidectomy was done if there were large residual thyroid tissues based on findings from postoperative ultrasonography.

Patients with a maximum diameter of primary tumour $1 \mathrm{~cm}$ or smaller (microcarcinoma) as measured by preoperative ultrasonography or postoperative data, distant metastasis, Graves' disease, ischemic heart disease or arrhythmia, or severe osteoporosis were excluded from the study. Written informed consent was obtained from all patients before enrolment.

\section{Pretreatment evaluation}

A complete medical history and physical examination with evaluation of the performance status were assessed.

Neck ultrasonography and chest x-ray were done for all the patients.

\section{Laboratory investigation}

Complete blood picture, serum creatinine, AST, ALT and bilirubin were done for all patients.

Free T4, free T3 and serum calcium levels were also tested.

\section{TSH analyses}

Serum TSH was determined with chemiluminescence immunoassay (CLIA) using microplate luminometers. The TSH CLIA test utilises a unique monoclonal antibody directed against a distinct antigenic determinant on the intact TSH molecule [14]. The mean TSH values based on 160 random normal adult blood samples is $2.2(0.27-$ 4.2) $\mu \mathrm{IU} / \mathrm{ml}$.

\section{Serum thyroglobulin ( $\mathrm{Tg}$ ) determination}

Serum Tg was measured by indirect solid phase enzyme immunometric assay. The assay is based on microplates coated with highly specific anti-human-thyroglobulin antibodies [15]. The mean $\mathrm{Tg}$ values based on 160 random normal adult blood samples is 28.8 (1.7-56) $\mathrm{ng} / \mathrm{ml}$.

Serum Tg was assessed in the same laboratory and using the same assay, during follow up of patients. Serum $\mathrm{TSH}$ was measured at the time of $\mathrm{Tg}$ determination. After total thyroid ablation by surgery and postoperative radioactive ${ }^{131} \mathrm{I}$, the $\mathrm{Tg}$ level should be $<1 \mathrm{ng} / \mathrm{ml}$ after TSH stimulation.

\section{Cardiac assessment}

Echocardiography and electrocardiography were done as a baseline and during follow-up examinations to 
verify the diagnosis of atrial fibrillation or any cardiac abnormality.

\section{Risk stratification}

The patients were classified according to AMES (age, metastases, extent and size) stratification system which included parameters that were available at our institution. Patients were considered at low risk, women younger than 50 years and men younger than 40 years without evidence of distant metastases. Also included in the low-risk group are older patients with primary tumours smaller than $5 \mathrm{~cm}$ and papillary cancer without evidence of gross extrathyroid invasion or follicular cancer without either capsular invasion or blood vessel invasion. Otherwise, the rest belonged to the high-risk group [16].

\section{Treatment administration}

\section{Postoperative radioiodine therapy (RAI)}

Postoperative ${ }^{131}$ I thyroid remnant ablation was given when the patient with a completely resected tumour, had a significant potential for recurrence (high-risk histology, vascular invasion and cervical lymph node metastases). Patients were treated with about $50-100 \mathrm{mCi}$ of ${ }^{131} \mathrm{I}$. In case of incomplete tumour resection, 150 to $200 \mathrm{mCi}$ was administered. That was followed after 5- to 7-day by whole body radioiodine scintigraphy.

TSH level should be more than $30 \mu \mathrm{lU} / \mathrm{ml}$. A lowiodine diet for 1-2 weeks is necessary before remnant ablation. Low iodine diets (<50 mg/d of dietary iodine) and simple recommendations to avoid iodine exposure (e.g., intravenous contrast, amiodarone use) should be prevented prior to RAI therapy to increase the effective radiation dose.

\section{Thyroxin therapy}

Levothyroxin (L-T4) therapy was started in doses according to treatment groups. Oral L-T4 treatment was taken once a day, in the morning on an empty stomach with water 30-60 minutes before breakfast. Daily intake of calcium (1200 mg/day) and vitamin D (1000 units/day) should also be given.

Patients were randomly assigned to receive postoperative TSH suppression therapy (Group I) or nonsuppression therapy (replacement dose) (Group II). Randomization was done using the block randomization method. L-T4 was given at an initial dose of $100 \mu \mathrm{g} / \mathrm{d}$ for patients with body weight under $50 \mathrm{~kg}, 150 \mu \mathrm{g} / \mathrm{d}$ for patients weighing $50-70 \mathrm{~kg}$, and $200 \mu \mathrm{g} / \mathrm{d}$ for patients weighing $70 \mathrm{~kg}$ or more. Serum levels of free T4, free T3 and TSH were done every 4 weeks. The daily dose of L-T4 is then adjusted in the patients of group (I) to suppress TSH levels to values below $0.1 \mu \mathrm{IU} / \mathrm{ml}$. While $\mathrm{TSH}$ level was adjusted to within the normal range (0.27-4.2 $\mu \mathrm{lU} / \mathrm{ml})$ for patients assigned to group (II).

\section{Patient follow-up}

A follow-up visit was conducted at 3-month intervals in the first 2 years, 6 months for the subsequent 3 years, and annually thereafter. Clinical examinations, ultrasonography of neck and thyroglobulin levels were done. Radioactive scans were done in the presence of elevated thyroglobulin level and clinical or radiologic evidence of recurrence or metastases. Before scanning stoppage of thyroxin therapy should be done so that TSH level became more than $30 \mu \mathrm{IU} / \mathrm{ml}$.

After adjusting the initial dose of L-T4, measuring serum TSH, were repeated every 3 months. Echocardiography was done to all patients to exclude cardiac complications. TSH was normalised for patients showing severe symptoms of thyrotoxicosis, cardiovascular disease (angina or atrial fibrillation) or progressive osteoporosis.

Disease-free status indicated the absence of distant metastases and no local recurrence or residual tumour. For solitary and accessible lesions surgery was attempted followed by additional radioiodine therapy aiming to cure. If the tumour could not be removed surgically, radioiodine therapy with about 150-200 mCi was given and repeated if necessary. External beam radiotherapy and or chemotherapy were administrated to inoperable recurrent disease, residual or metastases which had not concentrated radioactivity.

The following data were registered including the age at diagnosis, sex, date of diagnosis, pathological types, tumour size, nodal state, types of surgery, serum Tg and TSH levels at regular intervals, date of cure, date of recurrence after cure, date of death, cause of death and date of last follow-up.

\section{Statistical analysis}

Statistical analysis was done by using Statistical Package for Social Science program version 15. Chi square test or Fisher's exact test was used when appropriate to examine relationship between qualitative variables. Primary endpoint of our analysis was diseasefree survival (DFS). DFS was measured from the date of disease-free status to the date of relapse at any site (locoregional or distant), death due to any cause or the date of last follow-up if no relapse or death occurred. The second endpoint was overall survival which was calculated from the date of diagnosis to the date of death due to any cause or the date of last follow-up in the survivors. 
The survival endpoints were analysed using Kaplan-Meier method and log-rank tests were used to compare the two survival curves. Univariate and multivariate analyses for prognostic factors which affect survival were determined using cox proportional hazards regression model. Differences were considered statistically significant, when $p$ was $\leq 0.05$.

\section{Results}

From November 2006 to December 2010, 148 eligible patients with pathologically operable differentiated thyroid carcinoma were enrolled into this study. These patients represented the total number of patients treated in the department during this period and fulfilled the eligibility criteria. Seventy-six patients were randomly assigned to receive postoperative TSH suppression therapy (Group I), and 72 patients were assigned to receive nonsuppression therapy (Group II). The treatment groups were well balanced in terms of age, sex, pathological types and tumour size (< or $\geq 4 \mathrm{~cm}$ ), type of surgery, capsular invasion, nodal status and the risk of recurrence stratification as shown in table (1).

In group I, thirteen patients (17.1\%) suffered from thyrotoxic symptoms in the form of palpitation, tremors, heat intolerance and nervousness. Four of them had generalised bone aches too. The dose of L-T4 was reduced to level of nonsuppressed TSH for two patients with ventricular hypertrophy and dysfunction and in a patient who developed atrial fibrillation.

During the period of follow up with a median 54 months (range from 24 to 86 months), disease recurrence was found in six patients who received TSH suppression therapy (Group I) $(7.9 \%)$, all of the six patients developed local recurrence in the thyroid bed while one patient also had lymph node recurrence. As regard to patients who received TSH as nonsuppression therapy (Group II), disease recurrences were detected in 13 patients (18.1\%), 9 of them had local recurrence and 4 had lymph nodes recurrence while distant metastases discovered in 6 patients. There were two deaths $(2.6 \%)$ in the group I (one of them died of locally advanced disease and the other one because of liver failure). While six deaths (8.3\%) were recorded in the group II of patients, four of them due to distant lung metastases, one due to locally advanced disease and another one developed cerebral stroke (table 2)._Analysis was performed on an intention-to-treat basis.

Disease-free survival at five years was $91 \%$ of patients in the group I and $78 \%$ in the group II, while overall survival at five years was $97 \%$ in the group I and $91 \%$ of patients in group II (table 2). DFS curves for patients without TSH suppression therapy did not reach statistically significant difference comparing with those for patients with the therapy $(p=0.09)$. The hazard ratio (HR) of recurrence was $0.39 ; 95 \%$ confidence interval (0.14-1.09) (Fig. 1).

After the classification of patients into low- and highrisk groups according to AMES risk-group stratification, it was found that DFS was similar for both groups in low risk patients. However, there was statistically significant difference between both groups for high-risk patients $(p=0.04)$. The HR of recurrence was $0.31 ; 95 \%$ confidence interval (0.10-0.99) (Fig. 2).

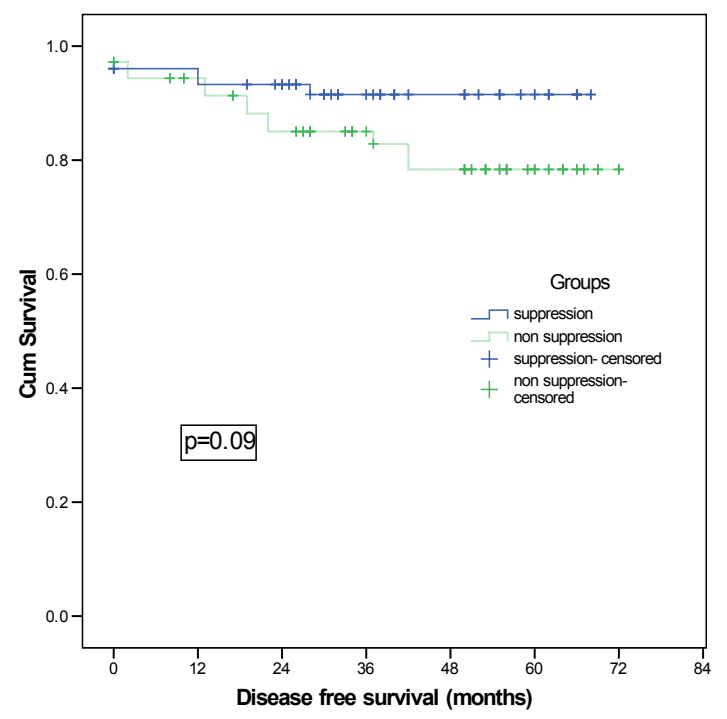

Figure 1: Disease-free survival in patients with and without TSH suppression therapy.

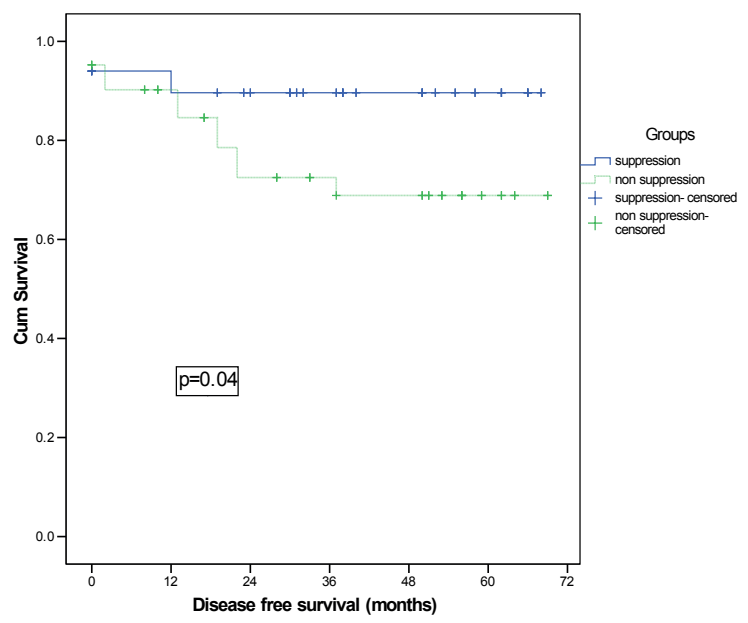

Figure 2: Disease-free survival in high-risk patients with and without TSH suppression therapy. 
Table 1: Baseline patients characteristics in both groups.

\begin{tabular}{|c|c|c|c|c|c|}
\hline \multirow[b]{2}{*}{ Characteristics } & \multicolumn{2}{|c|}{$\begin{array}{c}\text { Group I } \\
\text { TSH suppression therapy }\end{array}$} & \multicolumn{2}{|c|}{$\begin{array}{l}\text { Group II } \\
\text { without TSH suppression therapy }\end{array}$} & \multirow[t]{2}{*}{ p value } \\
\hline & No. of patients $(n=76)$ & (\%) & No. of patients $(n=72$ & (\%) & \\
\hline \multicolumn{6}{|l|}{ Age (years) } \\
\hline$<45$ & 48 & $(63.2)$ & 48 & $(66.7)$ & 0.66 \\
\hline$\geq 45$ & 28 & $(36.8)$ & 24 & (33.3) & \\
\hline \multicolumn{6}{|l|}{ Sex } \\
\hline Female & 60 & $(78.9)$ & 58 & $(80.6)$ & 0.81 \\
\hline Male & 16 & $(21.1)$ & 14 & $(19.4)$ & \\
\hline \multicolumn{6}{|l|}{ Tumour pathology } \\
\hline Papillary carcinoma & 59 & $(77.6)$ & 62 & $(86.1)$ & 0.18 \\
\hline Follicular carcinoma & 6 & $(7.9)$ & 4 & (5.6) & \\
\hline Follicular variant papillary & 8 & $(10.5)$ & 4 & (5.6) & \\
\hline Hurthle cell carcinoma & 3 & (3.9) & 2 & $(2.8)$ & \\
\hline \multicolumn{6}{|l|}{ Tumour size } \\
\hline Less than $4 \mathrm{~cm}$ & 47 & $(61.8)$ & 47 & $(65.3)$ & 0.66 \\
\hline More than $4 \mathrm{~cm}$ & 29 & $(38.2)$ & 25 & $(34.7)$ & \\
\hline \multicolumn{6}{|l|}{ Type of thyroidectomy } \\
\hline Total or near total & 46 & $(60.5)$ & 50 & $(69.4)$ & 0.26 \\
\hline Less than near total & 30 & $(39.5)$ & 22 & $(30.6)$ & \\
\hline \multicolumn{6}{|l|}{ Lymphadenectomy } \\
\hline Dissection & 26 & $(34.2)$ & 22 & $(30.6)$ & 0.64 \\
\hline No dissection & 50 & $(65.8)$ & 50 & $(69.4)$ & \\
\hline \multicolumn{6}{|l|}{ Capsular invasion } \\
\hline No & 70 & $(92.1)$ & 66 & $(91.7)$ & 0.92 \\
\hline Present & 6 & (7.9) & 6 & (8.3) & \\
\hline \multicolumn{6}{|l|}{ Lymph nodes status } \\
\hline Negative & 54 & $(71.1)$ & 50 & $(69.4)$ & 0.83 \\
\hline Positive & 22 & (28.9) & 22 & $(30.6)$ & \\
\hline \multicolumn{6}{|l|}{ Risk of recurrence* } \\
\hline Low & 26 & $(34.2)$ & 30 & $(41.7)$ & 0.35 \\
\hline High & 50 & $(65.8)$ & 42 & (58.3) & \\
\hline
\end{tabular}

*AMES risk group classification (low-risk/high-risk).

There was not statistically significant difference with regard to overall survival in patients without TSH suppression therapy compared with patients with the suppression therapy $(p=0.17)$ as shown in figure (3).

The age of the patients more than 45 years, tumour size more than $4 \mathrm{~cm}$ and high-risk group were significant independent predictor for thyroid carcinoma-related relapse in univariate analysis (Table 3), however, tumour size more than $4 \mathrm{~cm}$ was the only significant factor in multivariate analysis.

\section{Discussion}

Well-differentiated thyroid carcinoma expresses TSH receptors on the cell membrane [17] and responds to TSH stimulation by increasing the expression of several thyroid-specific proteins, including thyroglobulin, and by increasing rates of cell growth and that is the concept behind using thyrotropin (TSH) suppression therapy. Thyroid hormone treatment has been applied to prevent DTC growth or spread based on multiple clinical and 
Table 2: Disease recurrence and death in patients with and without TSH suppression therapy.

\begin{tabular}{|c|c|c|c|c|c|}
\hline \multirow{2}{*}{\multicolumn{2}{|c|}{ Total cases with disease recurrence }} & \multicolumn{2}{|c|}{$\begin{array}{c}\text { Group I } \\
\text { TSH suppression therapy } \\
(\mathrm{n}=76) \\
\text { No. (\%) }\end{array}$} & \multicolumn{2}{|c|}{$\begin{array}{c}\text { Group II } \\
\text { without TSH suppression } \\
\text { therapy }(n=72) \\
\text { No. (\%) }\end{array}$} \\
\hline & & 6 & (7.9) & 13 & $(18.1)$ \\
\hline High-risk patients & & $5 / 50$ & & $11 / 42$ & \\
\hline Low-risk patients & & $1 / 26$ & & $2 / 30$ & \\
\hline \multirow[t]{2}{*}{ 5-year DFS } & & $91 \%$ & & $78 \%$ & \\
\hline & Thyroid bed & 6 & & 9 & \\
\hline \multirow[t]{2}{*}{ Site of recurrence } & LN & 1 & & 4 & \\
\hline & Distant & 0 & & 6 & \\
\hline Total no. of deaths & & 2 & (2.6) & 6 & (8.3) \\
\hline 5-year OAS & & $97 \%$ & & $91 \%$ & \\
\hline
\end{tabular}

The recurrence in a patient may occur in more than one site.

Table 3: Univariate analysis of prognostic factors affecting the disease-free survival.

\begin{tabular}{|c|c|c|c|c|c|}
\hline Factor & Wald & $\operatorname{Exp}(B)$ & \multicolumn{2}{|c|}{$\begin{array}{c}95 \% \mathrm{Cl} \text { for } \\
\operatorname{Exp(B)}\end{array}$} & P value \\
\hline Patients age & 5.535 & 2.989 & 1.201 & 7.443 & $0.019 *$ \\
\hline Sex & 0.411 & 1.397 & 0.503 & 3.881 & 0.521 \\
\hline $\begin{array}{l}\text { Pathological } \\
\text { types }\end{array}$ & 1.045 & 0.652 & 0.287 & 1.481 & 0.307 \\
\hline Tumour size & 8.937 & 4.388 & 1.664 & 11.570 & $0.003^{*}$ \\
\hline $\begin{array}{l}\text { Capsular } \\
\text { invasion }\end{array}$ & 0.930 & 24.211 & 0.037 & 5.729 & 0.335 \\
\hline $\begin{array}{l}\text { Lymph node } \\
\text { invasion }\end{array}$ & 2.048 & 1.946 & 0.782 & 4.841 & 0.152 \\
\hline $\begin{array}{l}\text { Surgical } \\
\text { interference }\end{array}$ & 1.758 & 1.840 & 0.747 & 4.533 & 0.185 \\
\hline $\begin{array}{l}\text { Risk of } \\
\text { recurrence }\end{array}$ & 4.495 & 3.801 & 1.106 & 13.059 & $0.034^{*}$ \\
\hline
\end{tabular}

*Significant difference ( $p \leq 0.05)$.

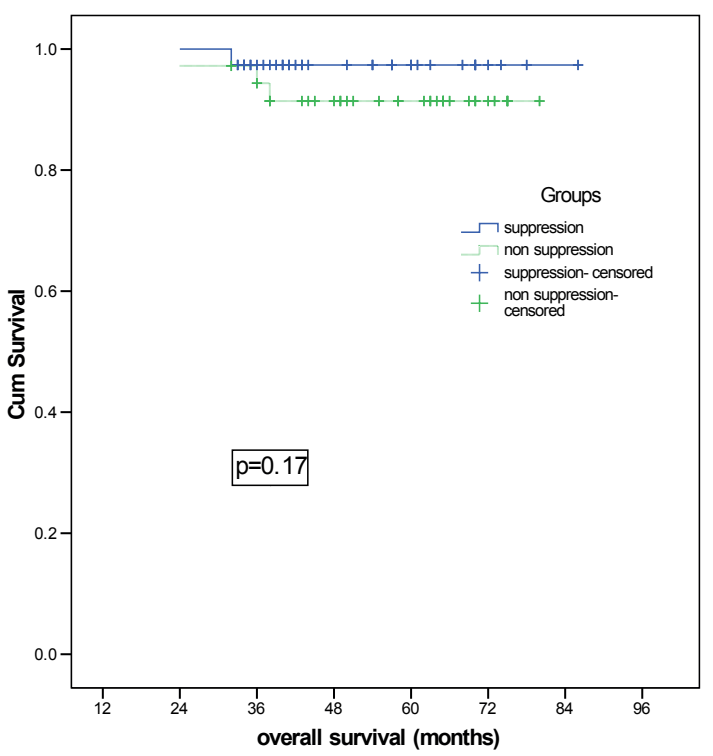

Figure 3: Overall survival in patients with and without TSH suppression therapy.

experimental observations [10]. Experimental studies have confirmed the expression and functional activity of TSH receptors in DTC and the proliferative effects of TSH on thyroid carcinoma cells in vitro [18-22].

In 1977, Mazzaferri et al collected multi-institutional retrospective data and reported that 5 years accumulated recurrence rates after initial surgery for papillary thyroid carcinoma (PTC) were significantly

lower for patients with TSH suppression therapy than for patients with no adjuvant therapy (approximately 10\% versus $20 \%$, respectively) [23]. However, recent studies have questioned the rationale for $\mathrm{TSH}$ suppression due to a number of findings; these include the fact that many thyroid cancers lack normal functioning TSH receptors and that $\mathrm{TSH}$ does not necessarily regulate thyroid growth per se but more likely thyroid cellular 
differentiation [24]. Thus, while the benefits of thyroid hormone are not disputed, the actual mechanism(s) by which thyroid hormone exerts its beneficial effects may need to be reconsidered [25].

So far, there was no consensus about the optimal serum TSH levels that is required for the initial treatment and follow-up of DTC despite several guidelines recommended the TSH suppressive levels. In high-risk patients who have persistent disease, the American Thyroid Association (ATA) and European Thyroid Association (ETA) recommend that the serum TSH level be kept at $<0.1 \mu \mathrm{lU} / \mathrm{ml}$. In high-risk but diseasefree patients, the ATA recommends TSH levels be kept at $0.1-0.5 \mu \mathrm{lU} / \mathrm{ml}$ for $5-10$ years, whereas the ETA recommends TSH levels $<0.1 \mu \mathrm{lU} / \mathrm{ml}$ for $3-5$ years. In low-risk and disease-free patients on follow-up, ATA and ETA both recommend serum TSH level be kept in the low normal range $(0.3-2.0 \mu \mathrm{lU} / \mathrm{ml})$ [16].

In this prospective study we investigated the effect of TSH suppression on both disease-free and overall survivals in patients with differentiated thyroid cancer after total thyroidectomy for high and low risk groups. Patients were classified into two groups according to the AMES risk-group classification to minimise any imbalance between groups [16]. Our study differed from earlier studies in being prospective, the homogeneity of the patient groups with respect to initial therapy [25-27], the study size, duration of follow-up and the patient's characteristics [28].

Before stratification of patients into high and low risk groups, TSH suppression therapy had a favourable influence on disease-free survival however it did not reach a statistically significant difference $(p=0.09)$. These results were similar to that noticed by a large meta-analysis studying the effect of TSH suppression therapy, performed by McGriff et al among 4174 patients with DTC, 2880 (69\%) were reported as being on TSH suppression therapy, and patients who received the therapy showed decreased risk of major adverse clinical events, including disease progression, recurrence and death (risk ratio, $0.73 ; 95 \% \mathrm{Cl}, 0.60-0.88 ; \mathrm{P}=0.05$ ). Unfortunately, all of the large cohort studies have been limited by a lack of randomization and a lack of appropriate controls. McGriff et al. concluded that the causal link between TSH suppression and reduction of major adverse clinical events was a probable association [9]. Similarly, Mazzaferri and Jhiang found fewer recurrences and thyroid carcinoma-related deaths in patients treated with TSH suppressive thyroxin dosages [29].

Traditional staging systems estimate the risk of death from thyroid cancer, but not necessarily the risk of recurrent disease. The seventh edition of the American
Joint Committee on Cancer/Union for International Cancer Control TNM system is most commonly used although other classification systems exist $[9,30]$. In this study, stratification of patients according to AMES riskgroup classification was done, it was found that DFS was similar for both groups in low risk patients. However, there was statistically significant difference between both groups for high-risk patients. There was not statistically significant difference with regard to overall survival in patients without TSH suppression therapy compared with patients with the therapy. Jonklaas et al also reported that superior outcomes were associated with aggressive TSH suppression in high-risk patients but were achieved with only modest suppression in stage II patients. They were unable to show any impact, positive or negative, of specific therapies in stage I patients [28].

Moreover, the Japanese demonstrated the equivalency of not performing TSH suppression therapy compared with performing the therapy. Based on their own risk-group definition and retrospective outcomes for patients with PTC, they have been recommending total thyroidectomy, RAI ablation and TSH suppression therapy in addition to locally aggressive surgery for every patient with high-risk PTC. Accumulation of these prospective outcomes and comparison with historical controls are an area of high priority. Considering that high-risk PTC becomes increasingly prevalent with age, strict suppression of TSH would increase the possibility of critical side effects such as cardiovascular disease and osteoporosis and still seems unlikely to decrease recurrence rates as much as has been expected [31].

According to univariate Cox regression analysis, age of patients, tumour size and high-risk group were significant independent predictors for thyroid carcinomarelated relapse; however they lost their significance in multivariate analysis except for the age factor. Hovens et al. showed that significant indicators for relapse in patients who were cured 1 year after initial therapy were extrathyroidal tumour extension (T4), the presence of distant metastases and older age. However when the significant variables obtained by univariate analysis were introduced into a stepwise multivariate model, T4, M1 and older age remained significant predictors for relapse [32].

The prognostic significance of lymph node status is controversial. One retrospective surgical series of 931 patients with DTC found that female gender, multifocality and regional node involvement are favourable prognostic factors. Poor prognostic factors included age older than 45 years, follicular histology, primary tumour larger than $4 \mathrm{~cm}$ (T2-T3), extrathyroid extension (T4) and distant metastases [33, 34]. Other studies, however, have shown that regional lymph node involvement had no 
effect or even an adverse effect on survival [29, 35-37].

In recent years, the concept of TSH-suppressive therapy has gradually changed, which recommends taking into account both the risk of recurrence or progression of DTC and the risk from adverse effects of L-T4 therapy. The risk for recurrence and progression in patients with DTC can be divided into three levels: low, intermediate and high risks, according to the ATA guidelines [6], and a similar assessment of the risk of adverse effects of L-T4 suppressive therapy can be also divided into low, intermediate and high risks, summarised by Biondi and Cooper. This can be called "double-riskadapted strategy" [13].

According to the double-risk-adapted strategy, TSH levels in patient with high or intermediate risk of recurrence or progression and no matter what risk of L-T4 related adverse effects, serum TSH levels should be kept $(<0.1 \mu \mathrm{lU} / \mathrm{ml})$. However, in patients with a high or intermediate risk of tumour progression and a high or intermediate risk of adverse effects from L-T4, the degree of TSH suppression should be adapted to the clinical situation, and cardiologic evaluation and bone

\section{References}

[1] Ibrahim AS, Khaled HM, Mikhail NN, Baraka $H$, Kamel H. Cancer incidence in Egypt: results of the National Population-Based Cancer Registry Program. J Cancer Epidemiol 2014; 2014:437971.

[2] Sherman SI. Thyroid carcinoma. Lancet 2003; 361(9356):501-511.

[3] Hundahl SA, Fleming ID, Fremgen AM, Menck HR. A National Cancer Data Base report on 53,856 cases of thyroid carcinoma treated in the U.S., 1985-1995. Cancer 1998; 83 (12):2638-2648.

[4] Esnaola NF, Cantor SB, Sherman SI, Lee JE, Evans DB. Optimal treatment strategy in patients with papillary thyroid cancer: a decision analysis. Surgery 2001; 130 (6): 921-930.

[5] Mazzaferri EL, Kloos RT. Clinical review 128: Current approaches to primary therapy for papillary and follicular thyroid cancer. J Clin Endocrinol Metab 2001; 86 (4):1447-1463.

[6] Cooper DS, Doherty GM, Haugen BR, Kloos RT, Lee SL, Mandel SJ, et al. Revised American Thyroid Association management guidelines for patients with thyroid nodules and differentiated thyroid cancer. American Thyroid Association (ATA) Guidelines Taskforce on Thyroid Nodules and Differentiated Thyroid Cancer. Thyroid 2009; 19(11):1167-1214. density assessment should be underwent periodically [38, 39]. Calcium and vitamin D are beneficial for osteoporosis patients, especially for postmenopausal patients. In patients with a low risk of cancer recurrence or progression and a high or intermediate risk of adverse effects, a TSH level of $0.5-1.0 \mu \mathrm{lU} / \mathrm{ml}$ would be reasonable. A TSH level of $0.1-0.5 \mu \mathrm{lU} / \mathrm{ml}$ is suggested in patients with a low risk of tumour recurrence and a low risk of adverse effects [40].

\section{Conclusion}

Suppressive treatment with L-T4 therapy in patients with differentiated thyroid carcinoma should be individualised and balanced against the adverse effects. TSH suppression is indicated in patients with high-risk disease or recurrent tumour. Normalisation of serum $\mathrm{TSH}$ is preferred for long-term treatment of disease-free elderly patients with DTC and comorbidities.

Conflict of interest: There is no conflict of interest.

[7] Hay ID, Thompson GB, Grant CS, Bergstralh EJ, Dvorak CE, Gorman CA, et al. Papillary thyroid carcinoma managed at the Mayo Clinic during six decades (1940-1999): temporal trends in initial therapy and long-term outcome in 2444 consecutively treated patients. World J Surg 2002; 26(8): 879-885.

[8] Wartofsky L, Van Nostrand D. Radioiodine treatment of well-differentiated thyroid cancer. Endocrine 2012; 42(3): 506-513.

[9] McGriff NJ, Csako G, Gourgiotis L, Lori CG, Pucino F, Sarlis NJ. Effects of thyroid hormone suppression therapy on adverse clinical outcomes in thyroid cancer. Ann Med 2002; 34(7-8): 554564.

[10] BiondiB, FilettiS, SchlumbergerM. Thyroid-hormone therapy and thyroid cancer: a reassessment. Nat Clin Pract Endocrinol Metab 2005; 1: 32-40.

[11] Collet TH, Gussekloo J, Bauer DC, den Elzen WP, Cappola AR, Balmer P, et al. Thyroid Studies Collaboration. Subclinical hyperthyroidism and the risk of coronary heart disease and mortality. Arch Intern Med 2012; 172(10):799-809.

[12] Sugitani I, Fujimoto Y. Effect of postoperative thyrotropin suppressive therapy on bone mineral density in patients with papillary thyroid carcinoma: 
a prospective controlled study. Surgery 2011; 150(6): 1250-1257.

[13] Biondi B, Cooper DS. Benefits of thyrotropin suppression versus the risks of adverse effects in differentiated thyroid cancer. Thyroid 2010; 20(2):135-146.

[14] Rongen HA, Hoetelmans RM, BultA, van Bennekom WP. Chemiluminescence and immunoassays. J Pharm Biomed Anal 1994; 12(4):433-462.

[15] Koszegi T. Immunoluminometric detection of human procalcitonin. J Biochem Biophys Methods 2002; 53(1-3):157-64.

[16] Cady B, Rossi R. An expanded view of risk-group definition in differentiated thyroid carcinoma. Surgery 1988;104: 947-953.

[17] Ichikawa Y, Saito E, Abe Y, Homma M, Muraki T. Presence of TSH receptor in thyroid neoplasms. J Clin Endocrinol Metab 1976; 42(2): 395-398.

[18] Carayon P, Thomas-Morvan C, Castanas E, Tubiana M. Human thyroid cancer: membrane thyrotropin binding and adenylate cyclase activity. J Clin Endocrinol Metab 1980; 51(4):915-920.

[19] Clark OH, Gerend PL, Goretzki P, Nissenson RA. Characterization of the thyrotropin receptoradenylate cyclase system in neoplastic human thyroid tissue. J Clin Endocrinol Metab 1983; 57(1):140-147.

[20] Roger P, Taton M, Van Sande J, Dumont JE. Mitogenic effects of thyrotropin and adenosine 3', 5'-monophosphate in differentiated normal human thyroid cells in vitro. J Clin Endocrinol Metab 1988; 66(6):1158-1165.

[21] Goretzki PE, Frilling A, Simon D, Roeher HD. Growth regulation of normal thyroids and thyroid tumors in man. Recent Results Cancer Res 1990; 118:48-63.

[22] Haugen BR, Pacini F, Reiners C, Schlumberger M, Ladenson PW, Sherman SI, et al. A comparison of recombinant human thyrotropin and thyroid hormone withdrawal for the detection of thyroid remnant or cancer. J Clin Endocrinol Metab 1999; 84(11): 3877-3885.

[23] Mazzaferri EL, Young RL, Oertel JE, Kemmerer WT, Page CP. Papillary thyroid carcinoma: the impact of therapy in 576 patients. Medicine (Baltimore) 1977; 56(3):171-196.

[24] Brabant G. Thyrotropin suppressive therapy in thyroid carcinoma: what are the targets? J Clin Endocrinol Metab 2008; 93(4): 1167-1169.

[25] Cooper DS. TSH suppressive therapy: an overview of long-term clinical consequences. Hormones 2010; 9(1):57-59.

[26] Pujol P, Daures JP, Nsakala N, Baldet L, Bringer
J, Jaffiol C. Degree of thyrotropin suppression as a prognostic determinant in differentiated thyroid cancer. J Clin Endocrinol Metab 1996; 81(12):43184323.

[27] Cooper DS, Specker B, Ho M, Sperling M, Ladenson PW, Ross DS, et al. Thyrotropin suppression and disease progression in patients with differentiated thyroid cancer: results from the National Thyroid Cancer Treatment Cooperative Registry. Thyroid 1998; 8(9):737-744.

[28] Jonklaas J, Sarlis NJ, Litofsky D, Ain KB, Bigos ST, Brierley JD, et al. Outcomes of patients with differentiated thyroid carcinoma following initial therapy. Thyroid 2006; 16(12):1229-1242.

[29] Mazzaferri EL, Jhiang SM. Long-term impact of initial surgical and medical therapy on papillary and follicular thyroid cancer. Am J Med 1994; 97 (5): 418-428.

[30] Lang BH, Chow SM, Lo CY, Law SC, Lam KY. Staging systems for papillary thyroid carcinoma: a study of 2 tertiary referral centers. Ann Surg 2007; 246(1): 114-121.

[31] Sugitani I, Kasai N, Fujimoto Y, Yanagisawa A. A novel classification system for patients with PTC: addition of the new variables of large $(3 \mathrm{~cm}$ or greater) nodal metastases and reclassification during the follow-up period. Surgery 2004; 135(2):139-148.

[32] Hovens GC, Stokkel MP, Kievit J, Corssmit EP, Pereira AM, Romijn JA, Smit JW. Associations of serum thyrotropin concentrations with recurrence and death in differentiated thyroid cancer. J Clin Endocrinol Metab 2007; 92(7): 2610-2615.

[33] Shah JP, Loree TR, Dharker D, Strong EW, Begg C, Vlamis V. Prognostic factors in differentiated carcinoma of the thyroid gland. Am J Surg 1992; 164 (6): 658-661.

[34] Andersen PE, Kinsella J, Loree TR, Shaha AR, Shah JP. Differentiated carcinoma of the thyroid with extrathyroidal extension. Am J Surg 1995; 170 (5): 467-470.

[35] Coburn MC, Wanebo HJ. Prognostic factors and management considerations in patients with cervical metastases of thyroid cancer. Am J Surg 1992; 164 (6): 671-676.

[36] Voutilainen PE, Multanen MM, Leppäniemi AK, Haglund $\mathrm{CH}$, Haapiainen RK, Franssila $\mathrm{KO}$. Prognosis after lymph node recurrence in papillary thyroid carcinoma depends on age. Thyroid 2001; 11 (10): 953-957.

[37] Staunton MD. Thyroid cancer. A multivariate analysis on influence of treatment on long-term survival. Eur J Surg Oncol 1994; 20 (6): 613-621. 
[38] Biondi B, Fazio S, Carella C, Sabatini D, Amato G, Cittadini A, et al. Control of adrenergic overactivity by beta-blockade improves the quality of life in patients receiving long term suppressive therapy with levothyroxine. J Clin Endocrinol Metab 1994; 78(5): 1028-1033.

[39] Gullu S, Altuntas F, Dincer I, Erol C, Kamel N. Effects of TSH-suppressive therapy on cardiac morphology and function: beneficial effects of the addition of beta-blockade on diastolic dysfunction. Eur J Endocrinol 2004; 150(5): 655-661.

[40] Kung AW, Yeung SS. Prevention of bone loss induced by thyroxine suppressive therapy in postmenopausal women: the effect of calcium and calcitonin. J Clin Endocrinol Metab 1996; 81(3): 1232-1236. 